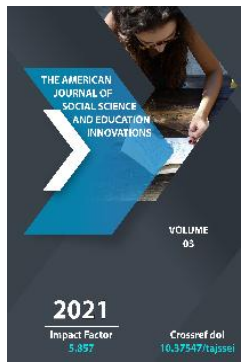

\title{
Learning The Educational Subject "Physics" Through Student Research
}

\author{
Beknozarova Zamira Farmonovna \\ Senior Lecturer, Tashkent Institute Of Irrigation And Agricultural Mechanization Engineers, \\ Tashkent City, Uzbekistan
}

\begin{abstract}
Journal Website:
http://theamericanjour

nals.com/index.php/taj

ssei

Copyright: Original content from this work may be used under the terms of the creative commons attributes 4.0 licence.
\end{abstract}

\section{ABSTRACT}

This article describes the essence of conducting student research through the teaching of physics, the issues of achieving goals and results by engaging students in the science they are studying.

\section{KEYWORDS}

Innovation, educational research, knowledge, physics, teacher, technology, module.

\section{INTRODUCTION}

The goal of education in modern society is the development of the personality of students, the realization of unique human capabilities, preparation for the complexities of life. After graduating from school, a student must deeply

assimilate the basic ideas of modern physics, master the system of scientific concepts, be able to navigate in scientific and technical 
literature, independently and quickly find the necessary information without any compulsion to replenish his knowledge and be able to quickly apply it in practice. We all know that a lesson is not only "the main form of organizing the educational process." It's also about the lessons we learn from organizing our lives. Learning this process begins at school. However, the problem is not the newness of the requirements, but the newness of their understanding. Indeed, the goal of learning has changed and, as you know, it consists not only in the accumulation of the sum of knowledge, skills and abilities, but in the preparation of the student as a subject of his educational activity. When studying physics, the task is to help students realize the importance and universality of the laws being studied, create conditions for the self-realization of the personality of each student in the learning process, develop the need for independent creative and research activities within the framework of physical science, and equip with the necessary methodological material. What do we have in reality? Lack of interest of students in the educational process, in knowledge and, therefore, for them the lessons are boring, not interesting, monotonous, do not aim at creativity.

To achieve these goals in my activities, I use the technology of student research, in the center of this technology is the personality of the child, striving for the maximum realization of his capabilities, open to the perception of a subjectively new experience. In my opinion, it contains elements of modern educational technologies, but one should not avoid elements of entertainment, as they arouse interest and curiosity among everyone, without exception, even among lowmotivated students. The most important thing is to get students interested in the content of the material being studied. This is possible due to the peculiarities of physical science, its universality, close connection with scientific and technological progress and everyday practical human activity.

I carry out my work in the following areas:

- Facing a problem.

- Data collection - "verification".

- Data collection - experimentation.

- Build an explanation.

- Socialization of the results obtained.

- Correction of research results.

Thus, the peculiarity of the application of the technology of student research is that the organization of research activities contributes to the formation of independent thinking of students, the development of mental operations. The main goal of the teacher in applying this technology is to prepare students for creative activity. At the same time, students act as researchers, independently obtaining knowledge, using a variety of sources and materials [1].

Cognitive activity of students within the framework of student research technology allows them to master the skills of planning and conducting research, the main stages of which are:

- Identification and formulation of the problem.

- Formulation of goals, objectives and research hypotheses.

- Conducting research, collecting data.

- Correlation of data and inferences, analysis and synthesis.

- Preparation and writing of a report, justification for solving problems. 
- Presentation with a preparatory message.

- Rethinking the research results in the course of answering questions, and through teaching classmates, testing hypotheses.

- Drawing conclusions, generalizations, conclusions.

Preparation for the application of student research technology in the study of a certain topic of a school physics course consists in:

- Highlighting physical knowledge in the content of teaching, which constitutes the information basis for the implementation of research tasks;

- Selection of research tasks, the implementation of which ensures the mastering of the curriculum by students;

- Preparing the necessary equipment and supplies for students;

- Choosing an indicative basis for the activities of students, taking into account their learning ability and training.

In case of thematic planning of training, educational knowledge of a topic or a small section of the program is distributed among the lessons.

The types of physics lessons when using this technology are: introductory lesson, performing experimental tasks, socialization lesson, generalization and systematization lessons, problem solving, laboratory work, independent work, control work [2].

For each training module, three or four research experimental tasks are allocated, performed by groups of students. Here is an example of a research experimental task for students in grade 9. The topic is "Equally Accelerated Rectilinear Motion".
Purpose of implementation: to establish the dependence of the speed of a material point (ball) on time.

Hypothesis: the assumption about the inconsistency of the speed of the ball.

Important information for students:

There are various types of mechanical movement: rectilinear and curvilinear; uniform and uniformly accelerated. The speed of change in the position of a material point in physics is characterized by speed (a quantitative characteristic of mechanical motion). Distinguish between the average and instantaneous speeds of a material point (speed at a given point of the trajectory or at a given time). The speed of the ball can be judged by the result of its action on other bodies, for example, by the bending of a curved elastic metal ruler (the displacement of the loose edge of the ruler is proportional to the speed of the ball).

In most cases, the movement of bodies, their speed changes with time. This dependence can be different: directly proportional, inversely proportional, quadratic, etc.

During the implementation of the experimental task, students must independently draw a conclusion about the dependence of the speed of the ball on time.

The maximum development of the cognitive powers of students can be achieved through the application of the research method with a skillful combination of class and extracurricular work. This nature of tasks in the lesson and in home research contributes to the development of the creative potential of schoolchildren.

Here are some forms of application of this teaching method.

Home practical work. Experience has shown that it is useful to give available experimental 
research as mandatory homework. The fact is that carrying out these works awakens the curiosity of all students, including those who are poorly performing, and the inclusion of more complex creative tasks allows gifted students to show their skills and knowledge. Moreover, many students complicate tasks on their own, introducing an element of personal creativity. Working with additional literature. Searching for materials, composing messages on a specific topic educate the skills of independent acquisition of knowledge and the ability to convey this knowledge to other students. Very often, the facts discovered by students arouse the genuine interest of all classmates or have an entertaining form. Using the methodology of student research in physics lessons, we can say with confidence that it allows you to solve all the problems assigned to the teacher.

\section{REFERENCES}

1. Zaprudsky N.I. Modern school technologies: A guide for teachers. Minsk: Ser-Vit, 2003 --- 288p.

2. Krotov V.M. Theory and practice of organizing independent cognitive activity of students in the study of physics. Mogilev: UO "Moscow State University. A.A. Kuleshova ", 2011. - 286 p. 